\title{
Avaliação da época de nascimento sobre o desenvolvimento corporal e os rendimentos pós-abate de cordeiros da raça Texel
}

\section{Gilson de Mendonça ${ }^{1,2}$, José Carlos da Silveira Osório²,3, Maria Teresa Moreira Osório²,3, Mabel Mascarenhas Wiegand ${ }^{4}$, Roger Marlon Gomes Esteves ${ }^{5}$, Carlos Eduardo da Silva Pedroso $^{4}$, Olívia Araújo 6}

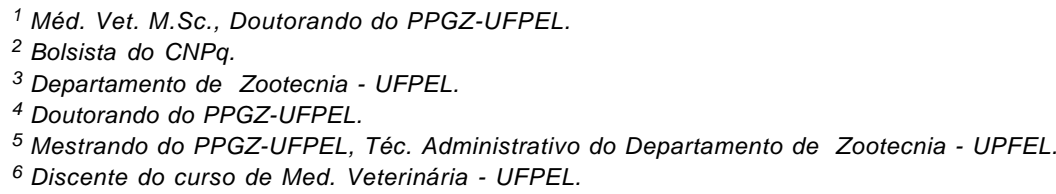

RESUMO - Para avaliar a viabilidade de épocas alternativas de nascimento sobre o desenvolvimento corporal e as características de carcaça de interesse comercial e dos componentes corporais em ovinos, foram utilizados 49 cordeiros machos Texel, não-castrados, nascidos em duas épocas (agosto e novembro). Os animais foram mantidos em pastagem e abatidos em dezembro para os cordeiros nascidos em agosto e abril para os nascidos em novembro, aos 129 e 164 dias de idade, respectivamente. Previamente aos abates, avaliou-se a produção forrageira do campo pelo método Botanal e verificaram-se melhores condições de forragem para os cordeiros nascidos em agosto. Esses cordeiros foram superiores quanto aos rendimentos comercial e verdadeiro, ao peso de carcaça quente e fria e quanto ao estado de engorduramento e cobertura de gordura da carcaça. O volume de vísceras verdes foi maior nos cordeiros nascidos em novembro, o que pode ser resultado da influência das condições nutricionais. A utilização de uma época alternativa de nascimentos para incrementar a oferta de cordeiros para o abate é viável em campo nativo melhorado.

Palavras-chave: morfologia, ovinos, rendimento

\section{Effect of different birth period on body development and carcass characteristics of Texel lambs}

\begin{abstract}
Forty-nine intact Texel lambs were used to evaluate the effects of different birth periods (August vs. November) on body development, body measurements and carcass characteristics. Animals were maintained in pasture and slaughtered in December for those born in August and April for those born in November at 129 and 164 days of age, respectively. Prior to slaughtering forage yield was estimated by the Botanal technique, which showed that animals born in August had access to better quality pasture. These lambs had greater retail and true carcass yields, hot and cold carcass weights, and carcass fat score and covering fat than those born in November. However, green viscera yield was higher in lambs born in November probably due to the observed differences in pasture nutritional conditions. It can be concluded that birth period affected carcass characteristics in the present trial.
\end{abstract}

Key Words: morphology, sheep, yield

\section{Introdução}

O setor da ovinocultura na Região Sul do Brasil, especialmente no Rio Grande do Sul, tem apresentado novo incremento ao direcionar as atenções para a produção de carne. A estacionalidade reprodutiva, aliada às condições ambientais da região, principalmente a sazonalidade da produção forrageira do campo nativo, determina a existência de uma única época de nascimentos e, conseqüentemente, a limitação no período de oferta de animais para o abate ao longo do ano (Machado, 1999).
A categoria ovina de maior aceitação no mercado consumidor é o cordeiro, que é também a mais rentável para o produtor de carne (Pilar et al., 2005). Entretanto, para otimização dos sistemas de criação e comercialização de ovinos para o abate, deve-se buscar a idade ou o peso corporal de abate em que os rendimentos de carcaça sejam economicamente os mais indicados.

Nem sempre as carcaças com maiores rendimentos são as melhores, pois normalmente verifica-se excessivo teor de gordura - em decorrência da idade e dos pesos elevados que deverá ser posteriormente removido (Jardim et al., 
2000). Ambos os fatores (idade e peso) devem ser considerados quando se busca uniformização e comercialização justa de um produto de qualidade (Osório et al., 1999). Almeida Jr. et al. (2004) observaram que o aumento na idade de abate influenciou negativamente o peso de carcaça quente e fria, o peso do corpo vazio e os rendimentos de carcaça quente e fria, indicando que os sistemas que possibilitam menor idade de abate devem ser tecnica e economicamente mais interessantes.

$\mathrm{O}$ aumento no peso corporal pode determinar alterações nas características de carcaça e de interesse comercial, como aumento no peso e rendimento de carcaça, na área de olho-de-lombo e na quantidade de gordura, melhora na conformação da carcaça e maior deposição de tecido por unidade de comprimento da carcaça (Motta et al., 2001; Osório et al., 2002b). Por outro lado, o peso corporal ao abate constitui, por si só, uma descrição inadequada do valor de um animal produtor de carne e, portanto, não é o critério mais justo de comercialização, pois não inclui a porcentagem dos diferentes componentes corporais e sua valorização (Roque et al., 1999; Osório et al., 2002a).

O elevado peso de determinados componentes corporais pode influenciar negativamente o rendimento de carcaça do animal. Segundo Carvalho et al. (1999), o trato digestório cheio e a pele são os componentes corporais que mais influenciam o rendimento de carcaça em ovinos.

O sistema de alimentação determina diferenças nos componentes corporais. Frescura et al. (2005) verificaram maior peso e porcentagem de pele e menor de conteúdo gástrico em cordeiros cruza Ile de France $\times$ Texel mantidos em pastagem cultivada em relação aos confinados. Motta et al. (2001) observaram efeito do sistema de alimentação sobre os pesos de carcaça em cordeiros Texel e verificaram que o melhor nível nutricional correspondeu ao maior peso de carcaça.

A raça é outro fator que pode influenciar os rendimentos pós-abate em cordeiros. Costa et al. (1999) registraram maiores valores absolutos para peso de carcaça quente, patas, vísceras verdes e vísceras vazias em cordeiros Texel que nas raças Corriedale e Ideal, que, por sua vez, apresentaram maiores valores para pele. Osório et al. (2002a), em experimento com cordeiros Border Leicester $\times$ Corriedale $\mathrm{e}$ Border Leicester $\times$ Ideal, encontraram maiores valores absolutos e percentuais para pele nos animais Border Leicester $\times$ Corriedale e atribuíram esse resultado ao maior comprimento e espessura de mecha da lã dos animais Corriedale.

Este trabalho foi realizado com o objetivo de verificar a viabilidade de épocas alternativas de nascimento sobre as características corporais, de carcaça e de interesse comercial e os componentes corporais de cordeiros Texel.

\section{Material e Métodos}

O experimento em sua fase de campo foi desenvolvido em uma propriedade particular de Santa Vitória do Palmar, RS, localizada entre os paralelos $32^{\circ} 32^{\prime} 00^{\prime \prime}$ norte e $33^{\circ} 45^{\prime}$ $00^{\prime \prime}$ sul. O clima predominante na região é o subtropical, com estações bem definidas e chuvas regulares ao longo do ano. A precipitação anual média é de $1.200 \mathrm{~mm}$ e os meses mais secos são dezembro e janeiro. As temperaturas oscilam entre -2 e $36^{\circ} \mathrm{C}$, com média de $23^{\circ} \mathrm{C}$ e ocorrência de geadas durante os meses de junho, julho e agosto.

Os campos são cobertos por vegetação nativa e apresentam variações qualitativas nos diferentes períodos do ano. Nos períodos de primavera e verão, são baixos e densos, formando uma cobertura natural de boa qualidade para exploração animal em pastagem. No inverno (junho a agosto), os campos não apresentam crescimento e ficam secos pela ocorrência de geadas, ocorrendo redução das áreas de campo em virtude do aumento nos depósitos naturais de água (lagoas e banhados), que são abundantes na região. Segundo Mohrdieck (1993), agrostologicamente, os campos da região são constituídos por elevado número de espécies rizomatosas e cespitosas de baixo porte, entre as quais destacam-se Paspalum notatum (grama boiadeira), Adesmia bicolor (babosa) e Desmodium trifolium (pega-pega).

A fase laboratorial do experimento foi desenvolvida no Laboratório de Carcaças e Carnes do Departamento de Zootecnia da Faculdade de Agronomia Eliseu Maciel, na Universidade Federal de Pelotas.

Foram utilizados 49 cordeiros Texel (SO), machos, nãocastrados, nascidos de partos simples em duas épocas distintas: agosto $(n=23)$ e novembro $(n=26)$ de 2004, provenientes de ovelhas acasaladas em março e junho, respectivamente. Os cordeiros foram pesados logo após o nascimento e em intervalos de 28 dias utilizando-se uma balança mecânica com capacidade para $500 \mathrm{~kg}$ e intervalos de peso de $100 \mathrm{~g}$.

Durante toda a fase de crescimento, os cordeiros permaneceram com suas mães sobre campo nativo melhorado, onde havia a ocorrência de Lolium multiflorum (azevém), Lotus corniculatus (cornichão) e Trifolium repens (trevo branco). A lotação média durante o período experimental foi de seis ovelhas + cordeiro/ha. Os animais nascidos em novembro foram desmamados aproximadamente aos 103 dias, durante o mês de fevereiro.

A avaliação da produção forrageira do campo foi realizada previamente a cada um dos abates, utilizando-se o 
método Botanal (Tothill et al., 1992) para obtenção da estimativa da produção de MS e da composição botânica do campo (Tabela 1).

Para determinação do momento do abate, foi utilizado como critério a condição corporal média do lote, de acordo com metodologia descrita por Osório \& Osório (2005). Na avaliação da condição corporal, foi atribuída nota de 1 a 5 , com escala de 0,5 , em que $1=$ excessivamente magra e $5=$ excessivamente gorda. A condição corporal escolhida como indicativo do momento para o abate foi de 3,0 e, quando atingida, todo o lote foi abatido após jejum de sólidos e dieta hídrica por um período de 14 horas.

Previamente ao abate, foi registrado o peso corporal de cada cordeiro e medidos a conformação in vivo (escala subjetiva de 1 a 5 , com intervalos de 0,5 , em que $1=$ muito pobre e $5=$ excelente), a condição corporal (conforme escala anteriormente descrita), o comprimento corporal $(\mathrm{cm})$, a altura do posterior $(\mathrm{cm})$, a altura do anterior $(\mathrm{cm})$, o perímetro torácico $(\mathrm{cm})$ e a compacidade corporal (peso corporal/ comprimento corporal, em kg/cm).

Após insensibilização mecânica, os cordeiros foram sacrificados por sangria e secção das artérias carótidas e veias jugulares. Seqüencialmente, foram realizadas a esfola, a evisceração e a separação da cabeça e das patas.

Imediatamente após o abate, foram pesados em balança digital os componentes pele, cabeça, vísceras verdes (inclu-

Tabela 1 - Composição botânica (em percentual por espécie) e quantidade de MS ( $\mathrm{kg} / \mathrm{ha})$ do campo nativo em cada uma das avaliações

Table 1 - Botanical composition (in species percentile) and amount of DM ( $\mathrm{kg} / \mathrm{ha}$ ) on native field in each evaluation

\begin{tabular}{|c|c|c|c|}
\hline $\begin{array}{l}\text { Mês de } \\
\text { avaliação } \\
\text { Month of } \\
\text { evaluation }\end{array}$ & $\begin{array}{c}\text { Composição } \\
\text { botânica } \\
\text { Botanical } \\
\text { composition }\end{array}$ & $\begin{array}{c}\text { Percentual } \\
\text { Percentile }\end{array}$ & $\begin{array}{c}\mathrm{MS}(\mathrm{kg} / \mathrm{ha}) \\
D M(\mathrm{~kg} / \mathrm{ha})\end{array}$ \\
\hline & $\begin{array}{l}\text { Azevém anual } \\
\text { Italian ryegrass } \\
\text { Trevo-branco }\end{array}$ & $\begin{array}{l}40,2 \\
15,9\end{array}$ & \\
\hline $\begin{array}{l}\text { Dezembro } \\
\text { December }\end{array}$ & $\begin{array}{l}\text { White clover } \\
\text { Cornichão } \\
\text { Birds foot trefoil } \\
\text { Cynodon dactylon } \\
\text { Cyperus }\end{array}$ & $\begin{array}{r}7,5 \\
16,5 \\
1,2\end{array}$ & 2.165 \\
\hline $\begin{array}{l}\text { Abril } \\
\text { April }\end{array}$ & $\begin{array}{l}\text { Cynodon dactylon } \\
\text { Piptochaetium } \\
\text { Setária geniculata } \\
\text { Oxalis spp } \\
\text { Outras gramíneas } \\
\text { Other grasses } \\
\text { Solo descoberto } \\
\text { Bare soil }\end{array}$ & $\begin{array}{r}38,7 \\
12,7 \\
9,0 \\
11,9 \\
12,7\end{array}$ & 1.365 \\
\hline
\end{tabular}

indo esôfago, compartimentos gástricos e intestinos delgado e grosso), patas, pulmões + traquéia, coração, fígado, baço, diafragma, pênis, testículos, bexiga e carcaça. Os rins e as gorduras pélvica e renal foram pesados após o resfriamento das carcaças, calculando-se a porcentagem de cada componente corporal em relação ao peso corporal ao abate.

As carcaças foram transportadas ao Laboratório de Carcaças e Carnes do Departamento de Zootecnia, FAEM - UFPEL, e depositadas em câmara fria, onde foram mantidas por 18 horas, a $1^{\circ} \mathrm{C}$ com ar forçado. Posteriormente, foram retiradas da câmara fria para determinação do peso de carcaça fria $(\mathrm{kg})$, da conformação (utilizando-se a mesma escala da conformação in vivo), do estado de engorduramento (escala subjetiva de 1 a 5 , com intervalos de 0,5 , em que $1=$ excessivamente magra e $5=$ excessinamente gorda), da compacidade da carcaça (peso de carcaça fria dividido pelo comprimento da carcaça, em $\mathrm{kg} / \mathrm{cm}$ ), do rendimento verdadeiro (peso de carcaça fria dividido pelo peso corporal ao abate, em \%) e da perda por resfriamento (peso de carcaça quente subtraído do peso de carcaça fria, em $\mathrm{kg} \mathrm{e} \mathrm{em} \mathrm{\% ).}$

As carcaças foram divididas longitudinalmente em duas meias-carcaças. As metades direitas foram avaliadas quanto ao comprimento interno da carcaça $(\mathrm{cm})$, ao comprimento da perna $(\mathrm{cm})$, à largura da perna $(\mathrm{cm})$ e à profundidade da perna $(\mathrm{cm})$. A meia-carcaça foi então seccionada entre a $12 \underline{a}$ e $13 \underline{a}$ costelas para determinação, na superfície do músculoLongissimus dorsi, da área de olho-de-lombo $\left(\mathrm{cm}^{2}\right)$, da espessura de gordura subcutânea (mm), da textura (escala subjetiva de 1 a 5 , com intervalos de 0,5 , em que 1 = muito grosseira e 5 = muito fina), do marmoreio (escala subjetiva de 1 a 5 , com intervalos de 0,5 , em que $1=$ inexistente e $5=$ excessivo) e da cor (escala subjetiva de 1 a 5 , com intervalos de 0,5 , em que $1=$ rosa-claro e 5 = vermelho-escuro).

Para avaliação do efeito das épocas de nascimento (agosto e novembro) sobre as características corporais, de carcaça e de interesse comercial e os componentes corporais, adotou-se o delineamento experimental completamente casualizado, em que a unidade experimental foi representada pelo cordeiro. O fator estudado foi a época de nascimento do cordeiro e o modelo estatístico utilizado para representar uma observação foi: $Y_{i j k}=\mu+E_{i}+\varepsilon_{i j k}$, em que $\mathrm{Y}_{\mathrm{ijk}}=$ uma observação de produtividade dos cordeiros, $\mu=$ média geral, $\mathrm{E}_{\mathrm{i}}=$ efeito da época de nascimento i do cordeiro $(i=1,2)$ e $\varepsilon_{i j k}=$ erro experimental. Para comparação de médias, foi aplicado o teste DMS de Fisher, pelo procedimento PROC GLM do SAS (2001), a 0,06 de significância. 


\section{Resultados e Discussão}

As médias para as características corporais obtidas nas épocas de nascimento avaliadas são listadas na Tabela 2. Os valores encontrados foram semelhantes aos registrados por Osório et al. (2005) em cordeiros Corriedale nascidos em agosto/setembro e levemente superiores para compacidade corporal. A maior compacidade pode ser explicada pela aptidão da raça Texel em produzir cordeiros pesados, com grande proporção de músculo, o que a caracteriza como eminentemente produtora de carne (Kremer et al., 2004).

Cordeiros nascidos em agosto tiveram maior comprimento corporal, enquanto os nascidos em novembro apresentaram maior altura do anterior e do posterior, indicando maior desenvolvimento das extremidades.Quando o aporte nutricional durante o crescimento é escasso, os órgãos e tecidos mais importantes, como o tecido ósseo, utilizam a maior parte desse aporte nutricional e, conseqüentemente, as regiões e os tecidos mais tardios, como a musculatura, sofrem inibição (Roque et al., 1999).Portanto, as diferenças em comprimento e altura entre os cordeiros podem ser atribuídas à menor taxa de crescimento dos animais nascidos em novembro, visto que, neste trabalho, os cordeiros nascidos em agosto apresentaram ganho médio diário significativamente maior em relação aos nascidos em agosto ( 0,260 vs $0,142 \mathrm{~kg} /$ dia, respectivamente).

Tabela 2 - Médias e erros-padrão para características corporais de cordeiros Texel nascidos em diferentes épocas do ano

Table 2 - Means and standard error of body measurements according to birth period

\begin{tabular}{|c|c|c|c|}
\hline \multirow[t]{2}{*}{$\begin{array}{l}\text { Característica } \\
\text { corporal } \\
\text { Body measurements }\end{array}$} & \multicolumn{2}{|c|}{$\begin{array}{c}\text { Época de } \\
\text { nascimento } \\
\text { Birth period }\end{array}$} & \multirow[t]{2}{*}{$\begin{array}{c}\text { Teste F } \\
\text { F test }\end{array}$} \\
\hline & $\begin{array}{l}\text { Agosto } \\
\text { August }\end{array}$ & $\begin{array}{l}\text { Novembro } \\
\text { November }\end{array}$ & \\
\hline $\begin{array}{l}\text { Peso corporal ao } \\
\text { abate }(\mathrm{kg})\end{array}$ & $35,07 \pm 0,97$ & $33,33 \pm 0,92$ & 0,2021 \\
\hline $\begin{array}{l}\text { Slaughter body weight } \\
\text { Comprimento } \\
\text { corporal }(\mathrm{cm})\end{array}$ & $58,2 \pm 1,0$ & $52,8 \pm 1,0$ & 0,0004 \\
\hline $\begin{array}{l}\text { Body length } \\
\text { Altura do posterior }(\mathrm{cm}) \\
\text { Posterior height }\end{array}$ & $49,17 \pm 0,69$ & $51,00 \pm 0,65$ & 0,0589 \\
\hline $\begin{array}{l}\text { Perímetro torácico }(\mathrm{cm}) \\
\text { Thoracic perimeter }\end{array}$ & $71,72 \pm 0,74$ & $70,85 \pm 0,70$ & 0,4000 \\
\hline Altura do anterior $(\mathrm{cm})$ & $55,17 \pm 0,62$ & $56,81 \pm 0,58$ & 0,0614 \\
\hline $\begin{array}{l}\text { Anterior height } \\
\text { Conformação (1-5) } \\
\text { Conformation }\end{array}$ & $3,9 \pm 0,1$ & $4,2 \pm 0,1$ & 0,2373 \\
\hline $\begin{array}{l}\text { Compacidade } \\
\text { corporal }(\mathrm{kg} / \mathrm{cm}) \\
\text { Body compactness }\end{array}$ & $0,602 \pm 0,012$ & $0,629 \pm 0,011$ & 0,1033 \\
\hline
\end{tabular}

Houve efeito da época de nascimento sobre os pesos de carcaça quente e fria, o estado de engorduramento da carcaça, a textura, a cor e a largura da perna, sendo obtidos valores superiores para os cordeiros nascidos em agosto (Tabela 3). Jardim et al. (2000), em experimento com cordeiros Corriedale, encontraram valores para estado de engorduramento semelhantes aos obtidos em cordeiros nascidos em novembro, porém, inferiores aos nascidos em agosto neste trabalho.

De acordo com Roque et al. (1999), quando a velocidade de crescimento é mais elevada, o animal deposita mais gordura e de forma mais rápida. A superioridade dos cordeiros nascidos em agosto quanto às características citadas pode ser atribuída à oferta forrageira, que diferiu entre as épocas.

Esses resultados são similares aos reportados por Osório et al. (2002b), que afirmaram que o aumento no peso corporal pode determinar alterações nas características de carcaça e de interesse comercial, como aumento no peso e no rendimento de carcaça, melhora na conformação e maior compacidade. Bueno et al. (2000) verificaram aumento linear para peso de carcaça quente e fria, assim como de seus cortes e componentes, o que denota acréscimo de tecidos nas carcaças com o aumento do peso corporal dos animais.

Os cordeiros nascidos em agosto apresentaram maior compacidade de carcaça. Ribeiro et al. (2001), em experimento com ovinos Ile de France e Hampshire Down, verificaram valores semelhantes aos deste estudo para essa característica. Os lotes não diferiram quanto às perdas por resfriamento ( $\mathrm{kg} \mathrm{e} \mathrm{\% );} \mathrm{os} \mathrm{valores} \mathrm{encontrados} \mathrm{foram} \mathrm{superiores} \mathrm{aos}$ relatados por Pilar et al. (2005) e Alves et al. (2003) e semelhantes aos obtidos por Osório et al. (2002a, 2005).

A espessura da gordura de cobertura foi maior nos cordeiros nascidos em agosto $(\mathrm{P}<0,05)$, provavelmente em virtude das diferenças nas condições nutricionais, que, por sua vez, podem ter sido a causa do maior ganho de peso nos cordeiros nascidos nessa época. Níveis nutricionais mais elevados determinam maior deposição de gordura na carcaça (Tonetto et al., 2004), portanto, quanto maior o ritmo de crescimento, maior e mais rapidamente será a deposição (Roque et al., 1999).

Zundt et al. (2003) verificaram maior cobertura de gordura na carcaça quando houve elevação do peso corporal ao abate, o que proporcionou carcaças com mais tecido adiposo. A gordura é um importante elemento de proteção da carcaça contra os efeitos adversos do frio, protegendo-a dos efeitos negativos da baixa temperatura de resfriamento e congelamento e da perda excessiva de água pela formação de cristais de gelo dentro das células (Sañudo et al., 2000; Rodrigues et al., 2006). 
Tabela 3 - Médias e erros-padrão para características da carcaça de cordeiros Texel nascidos em diferentes épocas do ano Table 3 - Means and standard errors for carcass characteristics in lambs according to birth period

\begin{tabular}{|c|c|c|c|}
\hline \multirow[t]{2}{*}{$\begin{array}{l}\text { Característica corporal } \\
\text { Body measurement }\end{array}$} & \multicolumn{2}{|c|}{$\begin{array}{c}\text { Época de nascimento } \\
\text { Birth period }\end{array}$} & \multirow[t]{2}{*}{$\begin{array}{l}\text { Teste } \mathrm{F} \\
\text { Ftest }\end{array}$} \\
\hline & $\begin{array}{l}\text { Agosto } \\
\text { August }\end{array}$ & $\begin{array}{l}\text { Novembro } \\
\text { November }\end{array}$ & \\
\hline Conformação da carcaça (1-5) (Carcass conformation) & $3,57 \pm 0,16$ & $3,56 \pm 0,15$ & 0,9721 \\
\hline Engorduramento da carcaça (1-5) (Carcass fat content) & $3,26 \pm 0,16$ & $2,71 \pm 0,15$ & 0,0131 \\
\hline Carcaça quente ( $\mathrm{kg})$ (Hot carcass) & $17,30 \pm 0,50$ & $14,40 \pm 0,50$ & 0,0003 \\
\hline Carcaça fria $(\mathrm{kg})$ (Cold carcass) & $16,50 \pm 0,50$ & $13,80 \pm 0,50$ & 0,0004 \\
\hline Rendimento verdadeiro (\%) (True carcass yield) & $49,10 \pm 0,50$ & $43,20 \pm 0,50$ & $<0,0001$ \\
\hline Rendimento comercial (\%) (Retail carcass yield) & $46,90 \pm 0,50$ & $41,30 \pm 0,50$ & $<0,0001$ \\
\hline Perdas por resfriamento (kg) (Cooling losses) & $0,74 \pm 0,05$ & $0,65 \pm 0,05$ & 0,2244 \\
\hline Perdas por resfriamento (\%) (Cooling losses) & $4,50 \pm 0,40$ & $4,50 \pm 0,40$ & 0,9391 \\
\hline Profundidade do peito $(\mathrm{cm})$ (Chest depth) & $25,80 \pm 0,46$ & $25,07 \pm 0,43$ & 0,2476 \\
\hline Comprimento da carcaça $(\mathrm{cm})$ (Carcass length) & $56,57 \pm 0,90$ & $55,06 \pm 0,85$ & 0,2288 \\
\hline Textura $(1-5)$ (Texture) & $4,57 \pm 0,06$ & $4,37 \pm 0,05$ & 0,0129 \\
\hline Cor $(1-5)$ (Color) & $1,98 \pm 0,06$ & $1,69 \pm 0,05$ & 0,0004 \\
\hline Largura da perna $(\mathrm{cm})$ (Leg width) & $10,07 \pm 0,19$ & $9,34 \pm 0,18$ & 0,0086 \\
\hline Marmoreio (1-5) (Marbling) & $1,72 \pm 0,09$ & $1,62 \pm 0,08$ & \\
\hline Comprimento da perna $(\mathrm{cm})($ Leg length $)$ & $34,10 \pm 0,50$ & $34,50 \pm 0,40$ & 0,5928 \\
\hline Profundidade da perna $(\mathrm{cm})($ Leg depth $)$ & $14,98 \pm 0,23$ & $14,53 \pm 0,22$ & 0,1593 \\
\hline Gordura de cobertura $(\mathrm{cm})$ (Covering fat) & $0,30 \pm 0,00$ & $0,00 \pm 0,00$ & $<0,0001$ \\
\hline
\end{tabular}

Osório et al. (2002b) relataram que o aumento no peso corporal pode determinar alterações em características da carcaça e de interesse comercial, como aumento no peso e no rendimento de carcaça e maior deposição de tecido por unidade de comprimento da carcaça (compacidade). Bueno et al. (2000) verificaram acréscimo linear positivo da compacidade com o incremento na idade de abate e no peso de carcaça fria em cordeiros Suffolk, denotando maior deposição de tecidos por unidade de comprimento. Cunha et al. (2001) afirmaram que a maior deposição de tecidos por unidade de comprimento se deve à maior deposição de gordura, e não de músculos.

Os cordeiros nascidos em agosto tiveram rendimentos comercial e verdadeiro superiores $(\mathrm{P}<0,05)$. Os valores obtidos para rendimento verdadeiro foram próximos aos descritos por Osório et al. (2002b) em cordeiros Corriedale $\times$ Ile de France e Pilar et al. (2005) em cordeiros Merino $\times$ Ile de France e superiores aos observados por Osório et al. (2005) em cordeiros Corriedale. A raça Texel é reconhecidamente uma das mais aptas para produção de carne e, de acordo com Nicoll et al. (1998), demonstra superioridade na proporção de carne comercializável em determinado peso de carcaça. Os valores obtidos para o rendimento comercial foram superiores aos descritos por Osório et al. (2005) e semelhantes aos reportados por Pilar et al. (2005) e Alves et al. (2003). Tonetto et al. (2004) encontraram valores superiores aos deste trabalho para cordeiros cruza Ile de France $\times$ Texel.

Uma das razões para esses resultados pode ser o menor conteúdo de vísceras verdes dos cordeiros nascidos nessa época. Sabe-se que as diferenças no rendimento podem ser atribuídas a variações nos componentes não-constituintes da carcaça. Osório et al. $(1998,1999)$ atribuíram as diferenças de rendimento de carcaça em cordeiros Ideal ao maior desenvolvimento do trato digestório dos animais criados em campo nativo em relação aos mantidos em pastagem cultivada. Tonetto et al. (2004) observaram maior rendimento de carcaça fria em animais mantidos em pastagem cultivada e atribuíram esse resultado principalmente ao menor conteúdo gastrintestinal e à maior deposição de gordura na carcaça, em razão do melhor nível nutricional disponibilizado aos animais, o que pode ter sido a razão, também neste trabalho, dos melhores rendimentos verdadeiro e comercial dos animais nascidos em agosto.

De acordo com Carvalho et al. (1999), o trato digestório cheioé um dos componentes corporais que mais influenciam o rendimento de carcaça em ovinos. Neste trabalho, as diferenças em quantidade, e principalmente qualidade da forragem disponível entre as épocas, podem ter determinado maior desenvolvimento das vísceras verdes nos cordeiros nascidos em novembro e menores rendimentos de carcaça nos animais nascidos nesse período.

Rosa et al. (2002) demonstraram que o desenvolvimento do aparelho digestório dos cordeiros é tardio e que, quanto maior o tempo para o grau de terminação adequado ser atingido, mais desenvolvido será o rúmen-retículo.Conseqüentemente, sua contribuição relativa ao peso vivo do animal será cada vez maior, contribuindo para a diminuição do rendimento de carcaça. 
Os cordeiros nascidos em agosto tiveram maiores pes os de cabeça e maiores pesos e percentual de patas, bexiga e pulmões+traquéia $(\mathrm{P}<0,05)$. Os cordeiros nascidos em no vembro apresentaram maiores percentuais de baço e rins e maiores pesos e percentuais de testículos e vísceras verdes (Tabela 4).

Os valores encontrados para pulmões + traquéia foram superiores e os de fígado inferiores aos obtidos por Alves et al. (2003) em cordeiros Santa Inês. Osório et al. (2002a), em cordeiros mestiços Border Leicester $\times$ Corriedale $\mathrm{e}$ Border Leicester $\times$ Ideal, encontraram valores semelhantes aos deste trabalho, do mesmo modo que Bueno et al. (2000) obtiveram para pele $(\mathrm{kg})$, patas $(\mathrm{kg}$ e \%) e fígado $(\mathrm{kg})$ em cordeiros Suffolk. Osório et al. (1996), em experimento com cordeiros Texel, encontraram valores inferiores para fígado, pele, patas, pulmões + traquéia e rins. Essas diferenças podem ser atribuídas ao efeito do genótipo dos animais, uma vez que esse é um dos fatores que mais afetam os componentes do peso corporal.

As diferenças entre as épocas de nascimento para determinados componentes corporais neste trabalho podem estar relacionadas à influência do fator nutricional. Os cordeiros nascidos em agosto apresentaram maiores valores de pele e gordura pélvica e renal, ambos em kg (Tabela 4), o que pode ser indicativo de melhores condições alimentares para este lote.

Mexia (2005) verificou efeito do sistema de alimentação sobre pulmões + traquéia e cabeça, tanto em \% quanto em $\mathrm{kg}$, e observou que cordeiros mantidos em pastagem com suplementação foram superiores aos confinados. Bueno et al. (2000) citaram aumento ou diminuição no percentual de determinados componentes corporais com o incremento no peso corporal ao abate. Segundo Roque et al. (1999), a precocidade aumenta em proporção direta ao aporte nutricional, determinando incremento no desenvolvimento dos tecidos tardios, como a gordura, quando as condições nutricionais são favoráveis.

As diferenças em vísceras verdes provavelmente estão relacionadas à qualidade da forragem ingerida, uma vez que os cordeiros nascidos em novembro encontraram composição forrageira desfavorável, com maior percentual de plantas invasoras e menor conteúdo de MS por ha (Tabela 1) em relação aos nascidos em agosto.

Osório et al. (1998; 2002b) relataram as diferenças que podem ser encontradas em vísceras verdes de acordo com o sistema de alimentação, de modo que, quanto menor a

Tabela 4 - Valores dos componentes corporais ( $\mathrm{kg} \mathrm{e} \%$ ) de cordeiros Texel nascidos em diferentes épocas do ano Table 4 - Values of body components ( $\mathrm{kg}$ and \%) of Texel lambs according to birth period

\begin{tabular}{|c|c|c|c|c|}
\hline \multirow[t]{2}{*}{$\begin{array}{l}\text { Característica corporal } \\
\text { Body measurement }\end{array}$} & & \multicolumn{2}{|c|}{$\begin{array}{c}\text { Época de nascimento } \\
\text { Birth period }\end{array}$} & \multirow[t]{2}{*}{$\begin{array}{c}\text { Teste F } \\
\text { F test }\end{array}$} \\
\hline & & $\begin{array}{l}\text { Agosto } \\
\text { August }\end{array}$ & $\begin{array}{l}\text { Novembro } \\
\text { November }\end{array}$ & \\
\hline Fígado & $(\mathrm{kg})$ & $0,51 \pm 0,02$ & $0,50 \pm 0,01$ & 0,8104 \\
\hline Liver & $(\%)$ & $1,45 \pm 0,03$ & $1,50 \pm 0,03$ & 0,2443 \\
\hline Baço & $(\mathrm{kg})$ & $0,06 \pm 0,00$ & $0,07 \pm 0,00$ & 0,0519 \\
\hline Spleen & $(\%)$ & $0,17 \pm 0,01$ & $0,20 \pm 0,01$ & 0,0022 \\
\hline Diafragma & $(\mathrm{kg})$ & $0,09 \pm 0,01$ & $0,10 \pm 0,01$ & 0,3447 \\
\hline Diaphragm & $(\%)$ & $0,25 \pm 0,02$ & $0,30 \pm 0,02$ & 0,1689 \\
\hline Pele & $(\mathrm{kg})$ & $4,19 \pm 0,13$ & $3,83 \pm 0,12$ & 0,0491 \\
\hline Skin & $(\%)$ & $11,97 \pm 0,22$ & $11,49 \pm 0,20$ & 0,1115 \\
\hline Pênis & $(\mathrm{kg})$ & $0,09 \pm 0,01$ & $0,07 \pm 0,01$ & 0,2553 \\
\hline Penis & $(\%)$ & $0,25 \pm 0,02$ & $0,22 \pm 0,02$ & 0,3769 \\
\hline Testículos & $(\mathrm{kg})$ & $0,19 \pm 0,02$ & $0,26 \pm 0,02$ & 0,0112 \\
\hline Testicles & $(\%)$ & $0,53 \pm 0,04$ & $0,75 \pm 0,04$ & 0,0007 \\
\hline Patas & $(\mathrm{kg})$ & $0,81 \pm 0,02$ & $0,72 \pm 0,02$ & 0,0004 \\
\hline Legs & $(\%)$ & $2,32 \pm 0,05$ & $2,17 \pm 0,05$ & 0,0446 \\
\hline Bexiga & $(\mathrm{kg})$ & $0,04 \pm 0,00$ & $0,02 \pm 0,00$ & 0,0001 \\
\hline Bladder & $(\%)$ & $0,10 \pm 0,01$ & $0,07 \pm 0,01$ & 0,0004 \\
\hline Cabeça & $(\mathrm{kg})$ & $1,38 \pm 0,04$ & $1,25 \pm 0,03$ & 0,0088 \\
\hline Head & $(\%)$ & $3,95 \pm 0,08$ & $3,76 \pm 0,08$ & 0,1082 \\
\hline Coração & $(\mathrm{kg})$ & $0,18 \pm 0,01$ & $0,18 \pm 0,01$ & 0,6956 \\
\hline Heart & $(\%)$ & $0,51 \pm 0,02$ & $0,54 \pm 0,02$ & 0,1821 \\
\hline Pulmões + traquéia & $(\mathrm{kg})$ & $0,68 \pm 0,02$ & $0,57 \pm 0,02$ & 0,0018 \\
\hline Lungs + trachea & $(\%)$ & $1,94 \pm 0,06$ & $1,71 \pm 0,05$ & 0,0047 \\
\hline Rins & $(\mathrm{kg})$ & $0,10 \pm 0,00$ & $0,10 \pm 0,00$ & 0,7498 \\
\hline Kidneys & $(\%)$ & $0,62 \pm 0,02$ & $0,72 \pm 0,02$ & 0,0003 \\
\hline Gordura pélvica e renal & $(\mathrm{kg})$ & $0,21 \pm 0,02$ & $0,16 \pm 0,02$ & 0,0638 \\
\hline Kidney and pelvic fat & $(\%)$ & $1,25 \pm 0,11$ & $1,16 \pm 0,10$ & 0,5512 \\
\hline
\end{tabular}


qualidade da forragem ingerida, maior o desenvolvimento desses componentes. Frescura et al. (2005) verificaram menor conteúdo gástrico em cordeiros mestiços Ile de France $\times$ Texel mantidos em pastagem cultivada em relação a confinados.

\section{Conclusões}

A utilização de diferentes épocas de nascimentos para incrementar a oferta de cordeiros para o abate não influencia os principais critériosin vivo (peso e condição corporal), o que possibilita obter animais similares para comercialização nas diferentes épocas do ano.

\section{Literatura Citada}

ALMEIDA JR., G.A.; COSTA, C.; MONTEIRO, A.L.G. et al Desempenho, características de carcaça e resultado econômico de cordeiros criados em creep feeding com silagem de grãos úmidos de milho. Revista Brasileira de Zootecnia, v.33, n.4, p.1048-1059, 2004.

ALVES, K.S.; CARVALHO, F.F.R.; FERREIRA, M.A. et al. Níveis de energia em dietas para ovinos Sant Inês: características de carcaça e constituintes corporais. Revista Brasileira de Zootecnia, v.32, n.6, p.1927-1936, 2003 (supl. 2).

BUENO, M.S.; CUNHA, E.A.; SANTOS, L.E. et al. Características de carcaça de cordeiros Suffolk abatidos em diferentes idades. Revista Brasileira de Zootecnia, v.29, n.6, p.1803-1810, 2000.

CARVALHO, S.; PIRES, C.C.; BERNARDES, R.A.C. et al. Desempenho e produção de lã de ovelhas lactantes e ganho e peso e características da carcaça dos cordeiros. Ciência Rural, v.29, n.1, p.149-153, 1999.

COSTA, J.C.C.; OSÓRIO, J.C.S.; SILVA, C.A.S. et al. Estudo da morfologia e características comerciais em cordeiros não castrados de quatro raças. Revista Científica Rural, v.4, n.2, p.105-112, 1999.

CUNHA, E.A.; BUENO, M.S.; SANTOS, L.E. et al. Desempenho e características de carcaça de cordeiros Suffolk alimentados com diferentes volumosos. Ciência Rural, v.31, n.4, p.671-676, 2001.

FRESCURA, R.B.M.; PIRES, C.C.; SILVA, J.H.S. et al. Avaliação das proporções dos cortes da carcaça, características da carne e avaliação dos componentes do peso vivo de cordeiros. Revista Brasileira de Zootecnia, v.34, n.1, p.167-174, 2005.

JARDIM, R.D.; OSÓRIO, J.C.S.; OLIVEIRA, N.M. et al. Características produtivas e comerciais de cordeiros da raça Corriedale criados em distintos sistemas nutricionais. Revista Brasileira de Agrociência, v.6, n.3, p.239-242, 2000.

KREMER, R.; BARBATO, G.; CASTRO, L. et al. Effect of sire breed, year, sex and weight on carcass characteristics of lambs. Small Ruminant Research, v.53, p.117-124, 2004.

MACHADO, L.A.Z. Manejo de pastagem nativa. Porto Alegre: Agropecuária, 1999. 158p.

MEXIA, A.A. Desempenho e características das fibras musculares e das carcaças em ovinos. Maringá: Universidade Estadual de Maringá, 2005. 82p. Tese (Doutorado em Zootecnia) Universidade Estadual de Maringá, 2005.

MOHRDIECK, K.H. Formações campestres do Rio Grande do Sul. In: FEDERACITE - CAMPO NATIVO, MELHORAMENTOE MANEJO. Porto Alegre: FEDERACITE, 1993. 108p.

MOTTA, O.S.; PIRES, C.C.; SILVA, J.H.S. et al. Avaliação da carcaça de cordeiros da raça Texel sob diferentes métodos de alimentação e pesos de abate. Ciência Rural, v.31, n.6, p.1051-1056, 2001.
NICOLL, G.B.; SKERRITT, J.W.; DOBBIE, J.L. et al. Effect of sire genotype on lamb growth and carcass productivity. Proceedings of the New Zealand Society of Animal Production, v.58, p.136-139. 1998.

OSÓRIO, J.C.; OLIVEIRA, N.M.; JARDIM, P.O. et al. Produção de carne em ovinos de cinco genótipos. II. Componentes do peso vivo. Ciência Rural, v.26, p.471-475, 1996.

OSÓRIO, J.C.S.; MARIA, G.; JARDIM, P. et al. Caracteres de crecimiento, sacrifício y canal em corderos de raza Corriedale criados en un sistema sostenible sobre pastos naturales de Rio Grande do Sul (Brasil). Información Técnica Económica Agraria, v.94, n.1, p.63-73, 1998.

OSÓRIO, J.C.S.; OLIVEIRA, N.M.; OSÓRIO, M.T.M. et al. Produção de carne em cordeiros cruza Border Leicester com ovelhas Corriedale e Ideal. Revista Brasileira de Zootecnia, v.31, n.3, p.1469-1480, 2002a (supl.).

OSÓRIO, J.C.S.; OSÓRIO, M.T.M.; OLIVEIRA, N.M. et al. Qualidade, morfologia e avaliação de carcaças. Pelotas: Universidade Federal de Pelotas, 2002b. 194p.

OSÓRIO, J.C.S.; OSÓRIO, M.T.M. Produção de carne ovina: técnicas de avaliação in vivo e na carcaça. 2.ed. Pelotas: Universidade Federal de Pelotas, 2005. 82p.

OSÓRIO, J.C.S.; OSÓRIO, M.T.M.; MENDONÇA, G. et al. Morfologia e características produtivas e comerciais em cordeiros Corriedale castrados e não castrados. Revista Brasileira de Agrociência, v.11, n.2, p.211-214, 2005.

OSÓRIO, M.T.M.; SIERRA, I.; SAÑUDO, C. et al. Influência da raça, sexo e peso/idade sobre o rendimento da carcaça em cordeiros. Ciência Rural, v.29, n.1, p.139-142, 1999.

PILAR, R.C.; PÉREZ, J.R.O.; NUNES, F.M. Rendimento e caracteres quantitativos de carcaça em cordeiros Merino Australiano e cruza Ile de France x Merino Australiano. Revista Brasileira de Agrociência, v.11, n.3, p.351-359, 2005.

RIBEIRO, E.L.A.; ROCHA, M.A.; MIZUBUTI, I.Y. et al. Carcaça de borregos Ile de France inteiros ou castrados e Hampshire Down castrados abatidos aos doze meses de idade. Ciência Rural, v.31, n.3, p.479-482, 2001

RODRIGUES, S.; CADAVEZ, V.; TEIXEIRA, A. Breed and maturity effects on Churra Galega Bragançana and Suffolk lamb carcass characteristics: killing-out proportion and composition. Meat Science, v.72, p.288-293, 2006

ROQUE, A.P.; OSÓRIO, J.C.S.; JARDIM, P.O. et al. Produção de carne em ovinos de cinco genótipos. 6. Desenvolvimento relativo. Ciência Rural, v.29, n.3, p.549-553, 1999.

ROSA, G.T.; PIRES, C.C.; SILVA, J.H. et al. Proporções e coeficientes de crescimento dos não-componentes da carcaça de cordeiros e cordeiras em diferentes métodos de alimentação. Revista Brasileira de Zootecnia, v.31, n.6, p.2290-2298, 2002.

SAÑUDO, C.; AFONSO, M.; SÁNCHEZ, A. et al. Carcass and meat quality ind light lambs from different fat classes in EU carcass classification system. Meat Science, v.56, n.1, p.89-94, 2000.

STATISTICAL ANALYSIS SYSTEM - SAS. SAS technical report. Release 8.01 TS Level 01MO. Cary: 2001. (CD-ROM).

TONETTO, C.J.; PIRES, C.C.; MÜLLER, L. et al. Ganho de peso e características da carcaça de cordeiros terminados em pastagem natural suplementada, pastagem cultivada de azevém (Lolium multiflorum Lam.) e confinamento. Revista Brasileira de Zootecnia, v.33, n.1, p.225-233, 2004.

TOTHILL, J.C.; HARGRAVES, J.N.G.; JONES, R.M. et al. BONTANAL - A comprehensive sampling and computing procedure for estimating pasture yield and composition. 1. Field sampling. Tropical Agronomy Technical Memorandum, v.78, 24p. 1992.

ZUNDT, M.; MACEDO, F.A.F.; MARTINS, E.N. et al. Características de carcaça de cordeiros terminados em confinamento, com dietas contendo diferentes níveis protéicos. Ciência Rural, v.33, n.3, p.565-571, 2003.

Recebido: 06/03/06 Aprovado: 09/02/07 